\title{
O051. Chronic migraine and onabotulinumtoxinA: a prospective study on patients treated at the Headache Centre of the Padua University and analysis of possible predictors of responsivity
}

\author{
Caterina Disco ${ }^{1 *}$, Matteo Bellamio ${ }^{1}$, Matteo Fuccaro ${ }^{1}$, Martina Bruno ${ }^{1}$, Alberto Terrin $^{1}$, Federico Mainardi ${ }^{2}$, \\ Giorgio Zanchin ${ }^{1}$, Ferdinando Maggioni ${ }^{1}$
}

From Abstracts from the 1st Joint ANIRCEF-SISC Congress

Rome, Italy. 29-31 October 2015

\section{Background}

Real clinical setting data about onabotulinumtoxinA treatment on chronic migraine are poor, especially in patients with medication-overuse headache $(\mathrm{MOH})$ and $\geq 65$ years old, as well as data on predictors of responsivity. W present results on chronic migraine patients treated at the Padua Headache Centre from April 2014 to March 2015.

\section{Materials and methods}

By compiling a headache diary, efficacy parameters (mean reduction of headache days and hours) were evaluated at 90 days after the first cycle. We analyzed also: $30 \%$ and $50 \%$ response rates and the percent of firsttime responders to II cycle; association with headache related symptoms and comorbidities (depression/anxiety disorders, hypertension, sleep disturbances, caffeine intake, BMI >30).

\section{Results}

Forty patients were evaluated ( $35 \mathrm{~F}, 5 \mathrm{M}$; mean age, $53 \pm 12.8$ ) of which $37 / 40$ (93\%) with $\mathrm{MOH}$. At 90 days after the first cycle headache diary documented a significant mean reduction of headache days (56.2 vs 69.2, $\mathrm{p}<0.005)$, of the total hours of headache (455.4 vs 601.6, $\mathrm{p}<0.005$ ), of the hours of moderate pain $(147.8$ vs $263.5, \mathrm{p}<0.005)$ and severe pain $(102.5 \mathrm{vs} 131.2, \mathrm{p}<0.05)$, of the consumption of triptans ( 30.7 vs $46.5, \mathrm{p}<0.001)$ and associations $(15.4$ vs $22.7, \mathrm{p}<0.05)$. The 8 patients $\geq 65$ years old did not present

\footnotetext{
* Correspondence: caterinadisco@gmail.com

${ }^{1}$ Department of Neurosciences, Headache Centre, University of Padua, Padua, Italy

Full list of author information is available at the end of the article
}

a significant reduction of efficacy parameters vs younger patients. $50 \%$ and $30 \%$ response rate was respectively $22.5 \%$ and $38 \%$ for at least one efficacy parameter, $15 \%$ and $25 \%$ for headache days, of $20 \%$ and $35 \%$ for hours, 12.5 and $23 \%$ for both parameters. Percent of "first-time 50\% responders" was $15.8 \%$ and $10.8 \%$ respectively for headache days and hours; percent of "first-time $30 \%$ responders" was $26.3 \%$ and $15.8 \%$. Cluster analysis showed a higher severe headache share and a lower share of mild headache in responsive patients vs non responsive: $146.7(26.3 \%)$ vs 119.1 (17.6\%) severe pain hours, 162.2 (29.1\%) vs 287.1 (41.1\%) mild pain hours. ANOVA analysis did not show significant association between responsivity and headache symptoms or related comorbidities, except for a lower response trend of depression/anxiety at limit of significance $(p=0.07)$.

\section{Conclusions}

OnabotulinumtoxinA treatment appears useful also in a clinical setting with high presence of $\mathrm{MOH}$. Responsive patients are $<65$ years old and have a higher frequency of severe headache and a lower share of mild headache. Depression/anxiety disorders are associated also to a lower responsiveness trend at limit of significance.

Written informed consent to publication was obtained from the patient(s).

\section{Conflict of interest}

The principal author declares that there is no conflict of interest.

\section{Authors' details}

'Department of Neurosciences, Headache Centre, University of Padua, Padua, Italy. ${ }^{2}$ Department of Neurology, Headache Centre, Hospital SS Giovanni and Paolo, Venice, Italy. 
doi:10.1186/1129-2377-16-S1-A98

Cite this article as: Disco et al: O051. Chronic migraine and onabotulinumtoxinA: a prospective study on patients treated at the Headache Centre of the Padua University and analysis of possible predictors of responsivity. The Journal of Headache and Pain 201516 (Suppl 1):A98.

\section{Submit your manuscript to a SpringerOpen ${ }^{\mathcal{O}}$ journal and benefit from:}

- Convenient online submission

- Rigorous peer review

- Immediate publication on acceptance

- Open access: articles freely available online

- High visibility within the field

- Retaining the copyright to your article

Submit your next manuscript at $\gg$ springeropen.com 